\title{
Glucose-6-Phosphate Dehydrogenase as Potential and Selective Target Against Malaria
}

\author{
Nelson A. N. de Alencara, Jordi Jimenez Juarez, Jeronimo Lameira Silva \& Javier Luque Garriga
}

\section{Introduction}

Science does not have a magic formula for malaria, Plasmodium parasites are developing unacceptable levels of resistance and many insecticides are no longer useful against mosquitoes that transmit the disease. Years of vaccine research have produced few hopeful candidates and although scientists are redoubling the search, an effective vaccine is years away. ${ }^{1}$ In response to this difficult situation, which in this study, we explored the pentose phosphate pathway of the malaria parasite Plasmodium falciparum (pf), in particular the Glucose-6-Phosphate Dehydrogenase enzyme (G6PD), in order to find a new potential therapeutic target and new alternative drugs. ${ }^{2}$

\section{Methods}

Was constructed the three dimensional structure of the enzyme pfG6PD using molecular homology modeling, with the MODELLER ${ }^{3}$ program and human enzyme in the same structure as a mold.

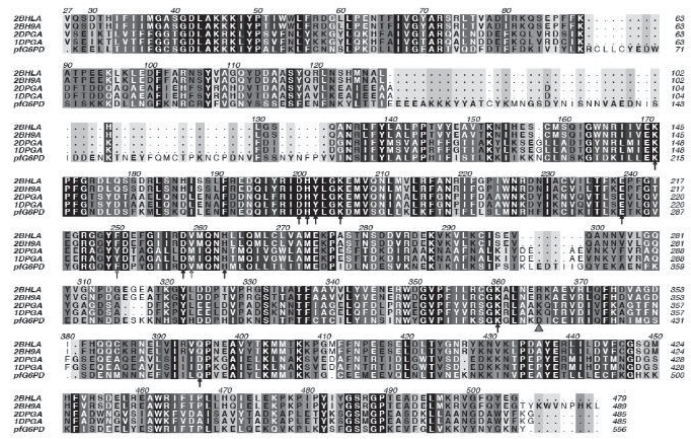

Figure 1. Multiple Align between pfG6PD and templates. Arrows show the active site. The red triangle presents most important residue for this study. The accentuated residues with blue were cut off for humanize the plasmodium.

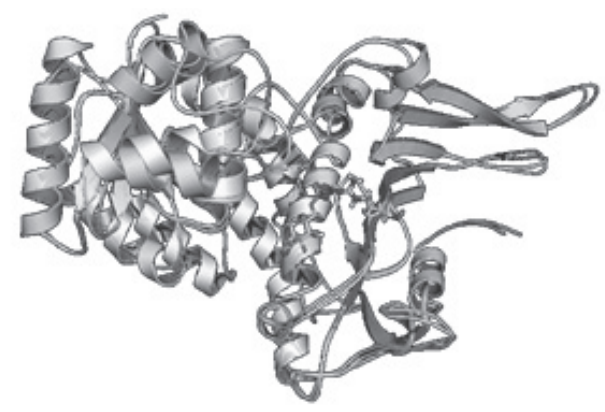

Figure 2. 3D Alignment between hG6PD and pfG6PD humanized hG6PD in Green cartoon, pfG6PD in yellow Cartoon and G6P in stick white. The key residue in this study is displayed under stick.

From the structural change of a single residue of the active site between the two enzymes (Arg365-h/Asp575pf), were proposed and complexed six selective inhibitors of the pfG6PD enzyme. Then studies of molecular dynamics (MD) using the method of molecular mechanics (MM) via the program $\mathrm{AMBER}^{4}$ and binding free energy calculations using the $\mathrm{SIE}^{5}$ method (solvated interaction energy). Time of Dynamic was $100 \mathrm{~ns}$.

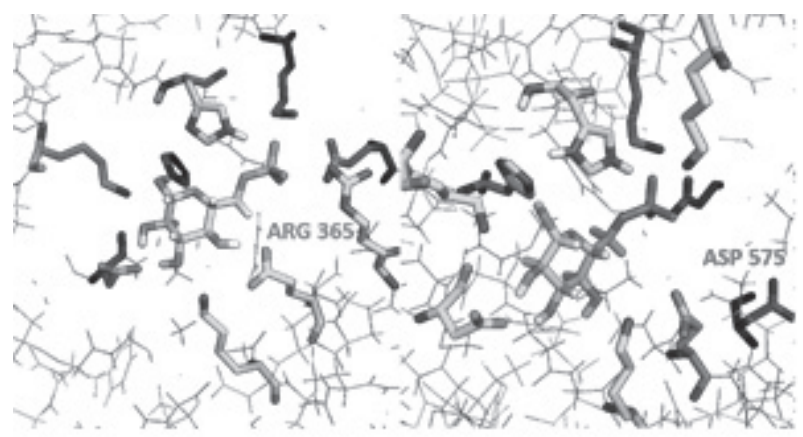

Figure 3. Active site of hG6PD and pfG6PD models complexed with G6P ligand, Show the structural change of a single residue of the active site Arg365-h (in Blue) and Asp575-pf (in Red) 


\section{Results and Discussion}

Results showed that the proposed model is satisfactory, both structurally and energetically, the mean values of free energy (SIE) for hG6PD and pfG6PD were -7.46 and $-7.71 \mathrm{kcal} / \mathrm{mol}$, respectively, compatible with the literature, 2 and site active well maintained with RMSD never exceeding $3 \AA$ for pfG6PD.

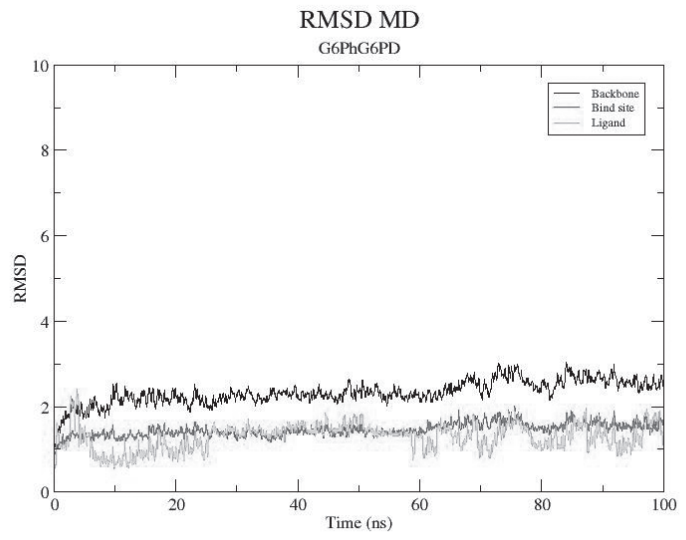

Figure 4. RMSD of hG6PD (black) complexed with the substrate G6P (green), red shows the RMSD of the active site, for a time of $100 \mathrm{~ns}$.

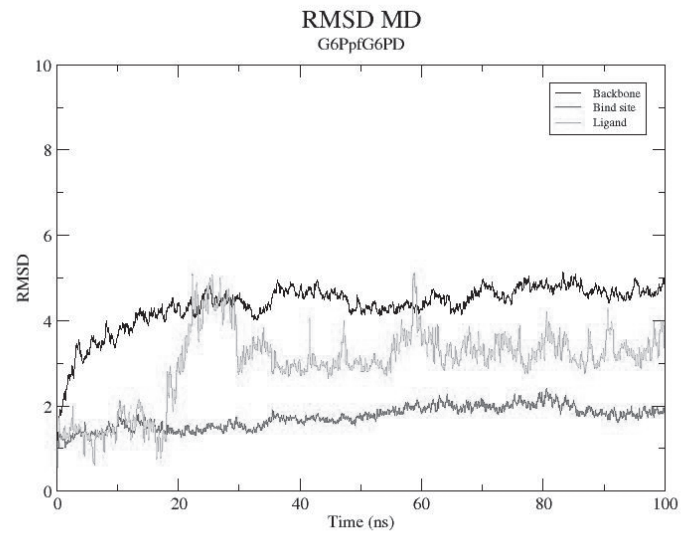

Figure 5. RMSD of pfG6PD (black) complexed with the substrate G6P (green), red shows the RMSD of the active site, for a time of $100 \mathrm{~ns}$.
The SIE results presented next to the values found in G6P-pfG6PD complex, with values below $-6 \mathrm{kcal} / \mathrm{mol}$ for the proposed inhibitors LIG3 and LIG6, values close to those found in the interaction of the enzyme with G6

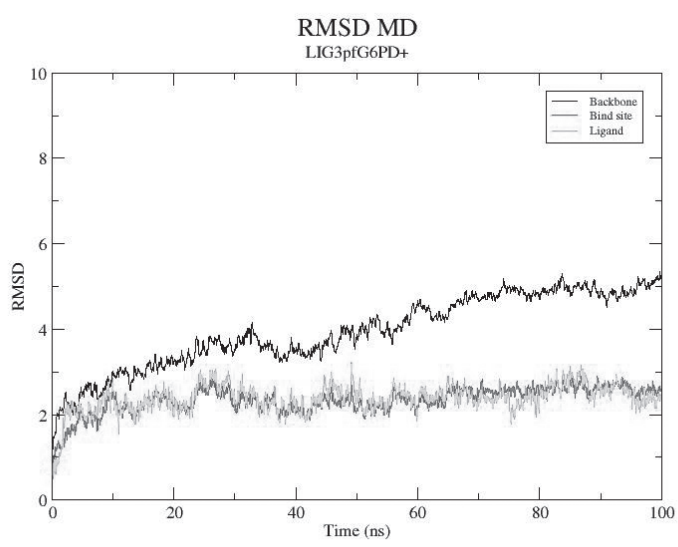

Figure 6. RMSD of pfG6PD (black) complexed with the ligand 3 (green), red shows the RMSD of the active site, for a time of $100 \mathrm{~ns}$.

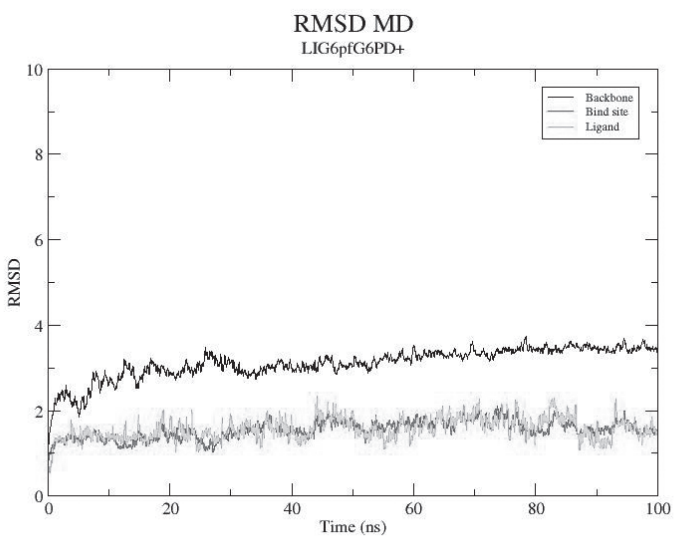

Figure 7. RMSD of pfG6PD (black) complexed with the ligand 3 (green), red shows the RMSD of the active site, for a time of $100 \mathrm{~ns}$.

\section{Conclusions}

In this study was constructed the 3D structure of Glucose-6-Phosphate Dehydrogenase enzyme of the plasmodium falciparum pfG6PD, that presented a significantly mutation in one residue in the active 


\section{Artigo Geral 43}

site, compared with the similar human enzyme. Were proposed six ligands for inhibit the pfG6PD enzyme. The best ligands were LIG 3 and 6, based with SIE method. The mutation of this single residue found in active site of pfG6PD can open a new path in search of the Plasmodium falciparum selective inhibitors and drug candidates against malaria. These binders are being synthesized and applied in studies of biological assay in vitro to confirm the possibility of inhibition, results will be presented in a next opportunity.

\section{Acknowledgments}

The authors acknowledge the financial support given by CAPES, FIBRA e UFPA

\section{References}

1. WHO, (2012). World Health Organization: Geneva, Switzerland.

2. PREUSS, J., E. JORTZIK (2012). IUBMB Life 64(7): 603-611.

3. SALI, A. ,T. L. BLUNDELL (1993). J Mol Biol 234(3): 779-815

4. CASE, D. A., ET AL (2005). J Comput Chem 26(16): 1668-1688

5. SULEA, T., PURISIMA E. (2012) Methods Mol Biol, 819, 295303.

\section{Nelson A. N. de Alencar ${ }^{a, b}$, Jordi Jimenez Juarez ${ }^{c}$, Jeronimo Lameira Silva ${ }^{a}$ \& Javier Luque Garriga ${ }^{c}$.}

\footnotetext{
a Universidade Federal do Pará- UFPA

${ }^{\mathrm{b}}$ Faculdade Integrada Brasil Amazônia (FIBRA)

${ }^{c}$ Universitat de Barcelona, Barcelona - Espanha.
} 